\title{
Organic agriculture in the system of the sustainable use of natural resources
}

\author{
Tatiana Polushkina, Yulia Akimova*, Elena Kovalenko, and Olga Yakimova \\ National Research Ogarev Mordovia State University, Saransk 430005, the Republic of Mordovia, Russia
}

\begin{abstract}
World experience indicates that the problems of ensuring sustainable development of agriculture have become an urgent need, therefore, the concepts of traditional technology for cultivating crops should be substantially revised not only from the standpoint of environmental management, but also to improve the economic situation in the industry. Greening of agriculture contributes to natural restoration of soil fertility, maintaining the balance of nature, on which agricultural economy largely depends. A growing quantity of farms in the USA, China, Russia, India, Japan and the EU countries conduct their farming in harmony with nature. The ultimate goals of their activities are ecologically balanced farming, animal husbandry and this agriculture industry technology acts as an alternative to traditional (industrial) farming. Development of organic agriculture involves the search and implementation of new technologies from a science-based position and due to the laws of optimal environmental management. In the article, the authors substantiate the need to enhance introduction of organic farming methods in order to ensure sustainable development and sustainable use of natural resources. Based on the study of foreign agriculture experience, the authors developed a number of key measures for the development of organic agriculture in Russian conditions.
\end{abstract}

\section{Introduction}

The problems of ensuring the sustainable development of agriculture have become an urgent need, therefore, the concepts of conventional cropping technology should be substantially revised not only from the standpoint of environmental management, but also from the point of improving the economic situation in the industry [1]. Greening of agriculture contributes to natural restoration of soil fertility, maintaining the balance of nature, on which agricultural economy largely depends.

A growing quantity of farms in the USA, China, Russia, India, Japan and the EU countries conduct their farming in harmony with nature. The ultimate goals of their activities are ecologically balanced farming, animal husbandry and this agriculture industry technology acts as an alternative to traditional (industrial) farming.

At the same time, the choice of organic agriculture in these countries does not mean a return to extensive technology. Development of organic agriculture involves the search and implementation of new technologies from a science-based position and due to the laws of optimal environmental management.

\section{Results}

As it is known, from the position of sustainable development, agriculture goes through several stages of development characterized by social, economic or environmental orientation. The first stage is associated with overcoming the problem of hunger or ensuring food security - countries of socially oriented agriculture are at this stage.

The countries of economically oriented agriculture are at the next stage, the main efforts are aimed at solving the problems of low level of well-being of workers in the agricultural sector. Finally, in the countries of ecologically oriented agriculture, the problem of minimizing environmental pollution as a result of agricultural activities is being solved.

Naturally, it is necessary to take into account that organic agriculture has a number of possible development restrictions. For example, due to lower productivity in organic farms compared to enterprises engaged in intensive production, the solution to the problem of poverty and hunger in the world is becoming more difficult (805 million people are starving or every 9th inhabitant of the planet). In Russia, food security is not fully ensured, so a complete transition to the production of organic products is not yet possible.

However, the growing significant demand for organic products on the world and domestic food markets (their sales for the period 2012-2016 increased almost in 5 times, while sales of inorganic products fell by $1.2 \%$ ) dictates the need to use organic principles of management in the production of high quality food.

There are objective conditions for the development of organic agriculture in Russia, among which there is the main resource - highly productive land withdrawn from circulation. Such lands are deficit all over the world. Moreover, $20 \%$ of the fresh water reserves, $9 \%$ of the planet's arable land, $58 \%$ of the world's black soil

* Corresponding author: yuaakimova@mail.ru 
reserves are concentrated in Russia as a whole. The amount of mineral fertilizers used in our country is 10 times less than in many countries of the world (for example, compared to the United States - 11 times less, with China - 23 times less) [2].

A very significant factor determining the possibility of developing organic agriculture in Russia is the availability of sufficient human resources in rural areas of the country: more than 6 thousand eco-settlements and farms, more than 18 thousand farmers, 4.5 million people involved in agriculture, about $10 \%$ of urban residents who are ready to move to the village.

Organic agriculture can become one of the potential growth points for rural settlements, as indicated in the Strategy for sustainable development of rural territories of the Russian Federation until 2030. Given that almost $40 \%$ of agricultural products in the country are produced in private smallholdings in compliance with some organic principles of management, the production of environmental products can be extremely important for raising the income level of rural workers.

Rural settlements make up more than $80 \%$ of the total number of municipalities of the country, being the main form of territorial organization of local selfgovernment. In these conditions, it is necessary to look for new effective ways of their development, and the State should create motivating mechanisms for selfdevelopment of rural territories in order to increase their competitiveness, as well as by stimulating the development of organic management methods [3].

Currently, about $1 / 3$ of the total pollution of nature has an impact on the agricultural sector of the economy [4]. In Russia, the annual economic damage from intensive agriculture exceeds 3 billion rubles. Improving the quality of life and health of Russians will be facilitated by improvement of the environmental situation in the regions due to the abandonment of fertilization, distribution of pesticides and other chemicals during organic agriculture development.

Organic agriculture can reduce the amount of energy spent on 1 hectare of cultivated land by almost 3 times (mainly due to the abandonment of application of synthetic mineral fertilizers and pesticides, as a result of the use of local feed and processing products), which will lead to a significant reduction of greenhouse gases emission [5].

Production processes that are independent of the supply of fertilizers, pesticides, herbicides, antibiotics, growth hormones etc. make agriculture less dependent on external economic factors [6]. The organic agriculture for modern Russia can also be considered as one of the elements of innovative development, since products with new consumer properties that are so useful for humans are starting to be offered on the food market.

In addition, organic agriculture can be conducted on the land of risky farming where industrial agriculture is unprofitable. Thirty years of world practice have proved that organic agriculture can develop in depressed regions provided that there is a favorable ecology.

\section{Discussion}

It should be noted that the idea of ecological farming is not new; it has its roots in the scientific works of the classics of domestic agricultural science too. The founder of Russian agronomic science, A.T. Bolotov (1738-1833), as early as 1771, in his work "On the fields' separation", formulated the basic principles of agroecology - farming in harmony with nature. This was Russia's first handbook on organizing of agricultural territory through the introduction of crop rotation. His ideas and action-oriented recommendations are still used abroad in the production of biologically complete and healthy products.

The issues of ecologization were further developed in the works of I. M. Komov (1750-1792), A.V. Sovetov (1826-1901), A.N. Engelgardt (1832-1893), P.A. Kostychev (1845-1842), V. V. Dokuchaev (18461903), I.A. Stebut (1833-1923) and others.

In Russia, among the scientific and practical ideas in the 20th and early 21 st centuries that are close to the notion of organic agriculture it should be noted grass rotation farming system developed before the war period by V.R. Williams (1863-1939).

In Germany, in the 1920s, biodynamic farming was developed as an early and still valid version of organic agriculture. Its theoretical provisions were developed by the Austrian scientist R. Steiner - the founder of anthroposophy. The biodynamic direction considers all living things as a well-balanced whole on the scale of not only earthly, but also cosmic relationships. It proceeds from the recognition of the Moon and stars influence on plants development linking it with the position of celestial bodies.

The social and practical foundation for the modern organic agricultural movement was laid in the 1940s in the publications of the British botanist Albert Howard, who spent a long time in India as an agricultural consultant. Studying local farming methods, he came to the conclusion that they were better than those offered by agricultural science. For advanced ideas and proposals to improve agricultural production, he earned the title of father of modern organic agriculture.

In 1939, Eva Balfour, under the influence of Howard's works, set up the world's first scientific experiment on agricultural land in the UK to compare conventional and organic agriculture. After 4 years, her book "Living Soil" was published. The work obtained a wide circulation and led to the founding of one of the most well-known organizations in organic agriculture today - the Soil Association.

In 1950, the Swiss couple Hans and Maria Muller developed biological methods of organic farming.

In 1968, the German microbiologist Hans-Peter Rush laid the foundations for bio-organic agriculture. In his book "Soil Fertility", he connected microbiology with soil fertility and also developed ideas about biological integrity, as well as the unity of food production and nature. 
In Japan, organic agriculture began developing about 100 years ago. An important contribution to its development was made by the philosopher Mokichi Okada. He paid special attention to the so-called "natural agriculture", the principles of which mostly comply with modern organic agriculture.

The term "organic agriculture" or "organic farming" was first used by the English scientist in the field of agriculture, Lord James Northbourne in his book "Take care of the land." He used this term not only in relation to organic fertilizers applied to the soil, but also as a concept of designing and farm management as an integrated system that combines soil, crops, animals and society. Today this systemic approach is fundamental to understand and make decisions in the field of organic agriculture.

A distinctive feature of organic agriculture is keeping soil fertility through the activation of biological methods of exposure [7]:

- minimization of soil cultivation, when soil fertility is maintained due to minimization of cultivation, taking into account its permissible level for different soil and climatic zones of the country; weed, pest and disease control; incorporation of organic fertilizers; coordination of the processing system with biological features of cultivated plants;

- instead of introducing nutrition elements in a directly digestible form, the replenishment of nutrition elements is provided mainly from 3 sources: various organic fertilizers; sparingly soluble minerals; nitrogenfixing plants;

- manure is recommended to be used in the form of compost, because, in addition to increasing the efficiency of its storage and digestibility by plants, the pollution of water bodies, atmospheric air with nitrogen compounds and their accumulation in the final commercial product are reduced;

- in conditions of a limited amount of manure, the role of straw increases as an organic fertilizer, which is more environmentally friendly when compared to manure, contains 3.4 times more organic matter;

- use of green manures in organic agriculture;

- use of peat and poultry manure in organic agriculture. Peat contains few nutrients available for plants, but it increases the humus content and improves soil structure. According to various estimates, there are 250 to 500 billion tons of peats in the world. Peatlands cover about $3 \%$ of the land area. In Russia, the leader in peat reserves, the share of land occupied by them in Tomsk region reaches $31.8 \%$ (Vasyugan Swamp), in Vologda region $-12.5 \%$. Finland is the world leader in peat extraction (30.6\%);

- crop rotation in organic agriculture;

- protection of crops against weeds, diseases and pests in organic agriculture conditions. The limited vision of conventional integrated plant protection methods has led researchers in sustainable agriculture to develop a bio-intensive integrated approach based on an environmental approach. Its essence lies in the fact that the main attention is paid to preventive measures; biological methods for regulating the number of pests are actively used; the least toxic materials are used to control their numbers. In organic agriculture, various methods can be used to prevent the spread of pests;

- breeding and seed production in organic farming. Organic agriculture does not require varieties with higher yields, primarily because of the risk of losing profits due to susceptibility to diseases. Varieties are needed that are characterized by higher crop stability by increasing adaptability to organic farming systems, which causes less yield loss;

- limitations of GMO use. The International Federation of Organic Agriculture Movements is opposed to genetic engineering because of the unprecedented danger it poses to the entire biosphere, as well as direct economic and environmental risks for the organic producers;

- ecological (organic) animal husbandry. In organic animal husbandry, it is unacceptable for animals to suffer and die. This moral aspect of relationships with rational beings determines special status of animals on the farm. These are living things that need to be taken care of, that can suffer, that can interact with each other and with people.

Currently, the trends in the development of organic production are topical in more than 180 countries of the world, and this figure is increasing annually due to the fact that organic products are becoming popular in many segments of the population for various objective reasons [8]. The area of lands under organic production in the world is growing constantly (Fig. 1).

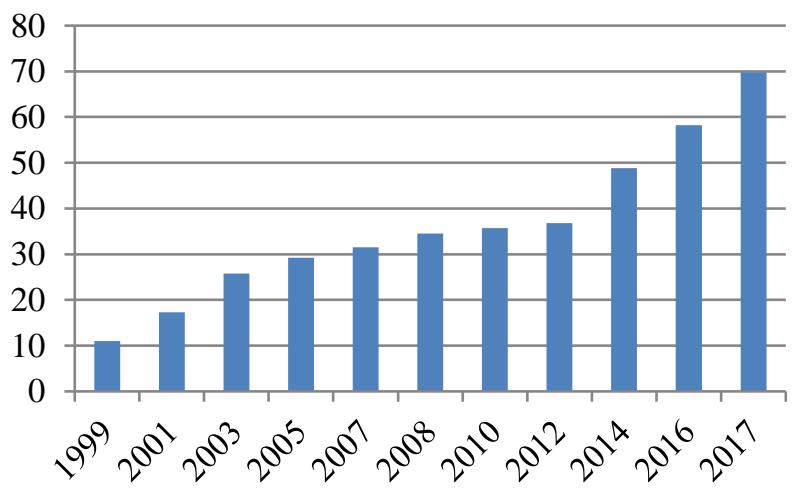

Fig. 1. Dynamics of agricultural land under organic production in the world, million hectares [9]

Thus, if in 2010, the total land area under organic production amounted to 35.7 million hectares, in $2017-$ 69.8 million hectares, which amounted to $1.4 \%$ of the total agricultural land in the world. Over the past 17 years, its area has increased more than 4 times, more than 2 million organic producers are certified. Nevertheless, currently, a little more than $1 \%$ of the global agricultural land is used for organic production.

According to FiBL and IFOAM data for 2017, countries such as Australia, Argentina, China, Spain, USA, Italy, Uruguay, India, France and Germany have more than 1 million hectares of land for organic production. As for the Russian Federation, 656.93 hectares of organic land are registered here. 
One of the largest centers for the development of organic agriculture is the European Union. More than $50 \%$ of all the farmers are actively involved in introducing new methods of rural development, which has been a political priority for the past 30 years. 112 million people live in rural areas, which comprise about $52 \%$ of the EU territory. They find work not only in agriculture, but also in the food industry and tourism, which employ about 15 million people. However, rural areas continue to face many social challenges, including high unemployment, declining incomes and lack of infrastructure and services.

Currently, the main types of organic land use in the EU are:

- arable crops - crops, mainly cereals, fresh vegetables, green fodder, legumes and oilseeds;

- permanent plantings - permanent crops such as fruit trees and berry plants, olive groves and vineyards;

- permanent pastures - pastures and meadows.

In 2017, organic land in the European Union was distributed as follows:

- among arable crops: cereals - 1.995 million hectares, grain legumes - 386.3 thousand hectares, oilseeds - 269.7 thousand hectares, green fodder 2.198 million hectares, root vegetables -38.5 thousand hectares, vegetables -158.9 thousand hectares;

- perennial crops: berries - 36.7 thousand hectares, citrus fruits -54.3 thousand hectares, temperate climate fruits - 101.5 thousand hectares, subtropical fruits 14.0 thousand hectares, grapes - 323.0 thousand hectares, nuts - 264.5 thousand hectares, olives 510.9 thousand hectares.

In 2017, compared to 2016, there was a significant increase in the area of oilseeds - by $19 \%$, root crops by $15 \%$, vegetables - by $17 \%$, subtropical fruits - by $17 \%$, nuts - by $13 \%$.

Next step is to consider the production of organic products in the EU countries.

The largest number of cattle is in Germany, France and Austria, but the highest share of organic cattle is in Latvia (25.1\%), Sweden (20.5\%), Austria (20.3\%) and Czech Republic (18.9\%). According to available data, pig production is highest in Denmark, Germany and France. As for organic poultry production, here we can distinguish France and Germany, and by share Denmark, Luxembourg and Sweden.

Organic cow milk is produced in all the European countries. Since 2008, it has almost doubled, which indicates a growing demand for milk and dairy products. By the end of 2017, milk production in the European Union reached 4.3 million tons, which is $3 \%$ of all its production in the region.

In 2017, the leaders among the EU countries in milk production were Germany - 939.1 thousand tons, France -678.8 thousand tons, Austria - 612.6 thousand tons, Denmark - 541.4 thousand tons, UK 492.0 thousand tons, Sweden - 414.2 thousand tons, Italy - 396,1 thousand tons (data for 2016), Netherlands - 247.8 thousand tons, Belgium 112.1 thousand tons.
All the EU countries have shown rising output of organic eggs. So, in 2017, the leaders were: France 1.38 billion pcs., Germany - 1.29 billion pcs., Netherlands - 883.0 million pcs., Denmark 307.9 million pcs., Austria -131.7 million pcs., Sweden - 380.1 million pcs., UK - 255.7 million pcs., Belgium - 121.9 million pcs.

Our country ranks 17 th in the world in the number of certified land and one of the first in its gain in 2014 2015 , but, unlike many countries, no less than $30 \%$ of certified land falls on future projects (Fig. 2). For example, in Moscow Region, more than 10 thousand hectares of land, which are not actually used in agriculture, are certified. This situation is typical precisely to our country, where there are a lot of lands. In European countries, the amount of certified land is almost equal to the amount of cultivated land [10].

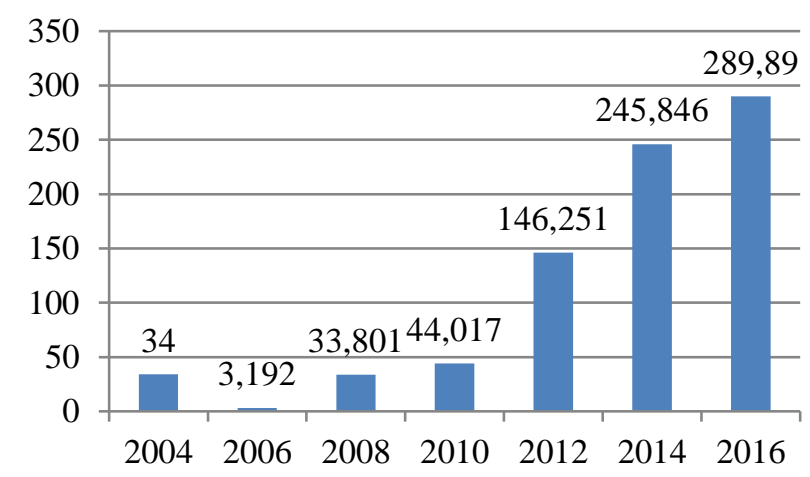

Fig. 2. Amount of certified land in the Russian Federation, thousand hectares

We are becoming like Europe in many structural positions. For example, in Europe, most households produce fruits, vegetables, cereals and dairy products, the same situation is in Russia:

- cereals and grain products $-23 \%$;

- fruits, vegetables, drinks - $22 \%$;

- dairy products - $13 \%$;

- meat and meat products $-11 \%$;

- processing - $11 \%$;

- wild plants $-6 \%$

- others $-14 \%$.

In Russia, the number of organic agricultural producers certified by international standards is more than 80. Most of them are in the field of plant growing. Profit from the production of organic products is obtained by those manufacturers who were able to establish vertical integration, including processing of products [10].

Such a quantity is, certainly, not enough to fill the market. The analysis shows that the consumption of organic products in Russia is growing at a good pace, and in order to improve the market situation, an annual increase in the number of certified enterprises to 200 per year is necessary. In this case, Russia will be able to come close to the performance of leading European countries over the course of $8-10$ years. However, today, the growth is $4-5$ enterprises per year only. This is largely due to the fact that the State practically does 
not participate in the formation of this direction of agriculture in our country. The USA and Europe live by other principle - they invest heavily in the development of this sector and provide state subsidies to organic farmers.

Organic agriculture will lead to the creation of a multifunctional agricultural economy with its full development and functioning. It will facilitate the organization and distribution of farms, small, medium and joint ventures, depending on the characteristics of the territories, natural resource and labor potential and the prospects of villages, zones and regions of the country. This approach will enrich the content and concept of a market type organic farming system and will allow achieving sustainable development and efficient use of useful territories in the long term.

\section{Conclusion}

Organic agriculture should be seen as an effective way of accumulating capital in rural areas where modern Russian private smallholdings produce more than half of all the agricultural products - in an amount not less than 1,850 trillion rubles with total production of 3.370 trillion rubles. Most of these products are produced in a natural way, which already creates a good base for organic agriculture. If at least $5 \%$ of agricultural producers can officially go into the high value-added sector of organic agriculture, then this will already give Russia's GDP increment of tens of billions of rubles. In the meantime, imports dominate the Russian market for organic products, often from raw materials produced in Russia. In this regard, it is necessary to develop state regulation measures for the development of organic agriculture which will contribute to increasing the efficiency of agricultural production, improving living standards of the rural population and preserving rural settlements.

The development of organic agricultural production will increase competitiveness of Russian agricultural products in the global food market, gaining new spheres of influence, improving the international image and investment climate by development of green economy. This will allow introducing the unused agricultural land into turnover. Moreover, different approaches should be used to stimulate the development of organic business principles in small business forms and large agricultural enterprises, taking into account their features. For the first ones, there should be developed such regulatory instruments that do not require significant funding and do not require the acquisition of additional knowledge.

As for agricultural enterprises, the production of their products associated with monocultures is on most of the areas. The strategies adequate to this method of land use can be more complex, based on the introduction of new high-tech methods of adaptive land use, monitoring, modern organizational structures, etc. Moreover, the level of their complexity should correspond to a specific management system and cultivated land complexity. It should be borne in mind that high-tech production does not necessarily imply a severe environmental impact.
And then there are questions whether it makes sense to increase productivity (of course, using environmentally acceptable technologies only) and where it is "more profitable" for the landscape (and, accordingly, for its user) to introduce alternative methods of management. Such methods may include a change in the organizational structure of the economy, and the introduction of other technologies, and a total phase-out of agricultural production. It is important that the strategic goal of any economy should be the increase of well-being of the rural population.

The defining Russian realities are the political, economic, social, natural heterogeneity of the territory, the weakness of the legal basis and imperfection of the taxation system. The general concept of development can consist only in the gradual transition of the existing low-tech management systems to adaptive farming systems. At the same time, existing environmental benefits should be used, for example, small amounts of mineral fertilizers and pesticides, expansion of existing, but not used areas with strict matching of farm opportunities with the landscape opportunities, and the gradual transfer of farms to the high-tech rails. The intensification should aim to reduce costs; the increase in yield cannot be an end in itself and should be carried out on the basis of the introduction of smart methods - strict monitoring of crops, compliance with agro technical measures, crop rotation, etc., as well as elite seed breeding.

\section{Acknowledgements}

The study was carried out with the financial support of the Russian Federal Property Fund and the Government of the Republic of Mordovia under the framework of scientific project No. 18-410-130002.

\section{References}

1. V. Strezov, A. Evans, T.J. Evans, Assessment of the Economic, Social and Environmental Dimensions of the Indicators for Sustainable Development, Sustainable development, 25, 242-253 (2017) Retrieved from: https://doi.org/10.1002/sd.1649.

2. A.G. Zeldner, World Economy: news, articles, statistics, analytics, The state of agricultural land in Russia. Retrieved from: http://www.webeconomy. $\mathrm{ru} /$ index.php?page $=$ cat $\&$ newsid=2492\& type $=$ news.

3. T.M. Polushkina, Organic agriculture in the system of sustainable development of rural areas, Problems of management theory and practice, 3, 133-142 (2016)

4. E.D. Lioutas, Ch.Charatsari, Green Innovativeness in Farm Enterprises: What Makes Farmers Think Green? Sustainable development, 26, 337-349 (2018) Retrieved from: https://doi.org/10.1002/sd.1709

5. A.V. Peshkova, Economic prerequisites for the development of organic agriculture in the regions of Russia, Int. Agricult. J., 1, 62-64 (2012) 
6. D.R. Lugo-Morin, Dynamics of Rural Communities Under Climate Change, Sustainable development, 24, 345-356 (2016) Retrieved from: https://doi.org/10.1002/sd.1609

7. J.E. Sokolova, Theory and practice of developing the global market for organic agriculture products, monograph (2012)

8. Joy R. Petway, Yu-Pin Lin, Rainer F. Wunderlich, Sustainability, Analyzing Opinions on Sustainable Agriculture: Toward Increasing Farmer Knowledge of Organic Practices in Taiwan-Yuanli Township,
11 (2019) Retrieved from: https://doi.org/ $10.3390 /$ su 11143843 .

9. Organic Agriculture Worldwide 2017: Current Statistics. Retrieved from: http://orgprints.org/ 33355/5/lernoud-willer-2019-global-stats.pdf.

10. T.M. Polushkina, E.G. Kovalenko, Yu.A. Akimova, S.A. Kochetkova, Environmentalization of Agriculture in Russia and the World, J. of Environm. Managem. and Tourism, 8, 537-553 (2017) Retrieved from: https://journals. aserspublishing.eu/jemt/article/view/1380. 